\title{
Atividade antibacteriana de desinfetantes para uso na produção orgânica de aves
}

\author{
Antibacterial activity of disinfectants for use in organic poultry keeping
}

Fátima Regina Ferreira Jaenisch ${ }^{\mathrm{I} *}$ Suzana Satomi Kuchiishi ${ }^{\mathrm{II}}$ Arlei Coldebella ${ }^{\mathrm{I}}$

\section{RESUMO}

A determinação de produtos eficazes para a desinfecção e que não causem danos ao meio ambiente é um grande desafio para a avicultura orgânica. Neste trabalho foram avaliadas as atividades antibacterianas de quatro desinfetantes: ácido peracético, amônia quaternária, hipoclorito de sódio a $1 \%$ e a $0,1 \%$ de cloro ativo e do composto de ácidos orgânicos (cítrico, lático e ascórbico), frente às amostras padrão de Escherichia coli, Salmonella enteritidis e Staphylococcus aureus, na presença e ausência de matéria orgânica, sob duas diferentes temperaturas e tempo de contato de 20 minutos. Os ácidos orgânicos mostraram-se menos efetivos na presença de matéria orgânica. No entanto, o ácido peracético, na ausência desta, foi o mais eficaz frente à $S$. Enteritidis e igualmente efetivo, independente da matéria orgânica, frente ao $\boldsymbol{S}$. aureus e $\boldsymbol{E}$. coli, revelando-se uma opção válida para desinfecção na avicultura orgânica, desde que precedida de limpeza criteriosa.

Palavras-chave: biodegradável, avicultura orgânica, Escherichia coli, Salmonella Enteritidis, Staphylococcus aureus.

\section{ABSTRACT}

Efficient products in the disinfection that do not cause damages to the environment are a challenge for the organic poultry keeping. The antibacterial activity of four disinfectants was evaluated to per acetic acid, quaternary ammonium, sodium hypochlorite at $1 \%$ and $0,1 \%$ and the composed of organics acids (citric, lactic and ascorbic) against standard samples of Escherichia coli, Salmonella enteritidis and Staphylococcus aureus in the presence and absence of organic matter, at two different temperatures and with 20 minutes of contact. Organic acids were shown less effective in the presence of organic matter. However, the per acetic acid in the absence of this revealed most efficient against $S$. Enteritidis and equally effective in the presence of organic matter, against S. aureus and $\boldsymbol{E}$. coli showing a valid option for disinfection in the organic poultry keeping since preceded of careful cleanness.

Key words: biodegradable, organic poultry keeping, Escherichia coli, Salmonella Enteritidis, Staphylococcus aureus.

\section{INTRODUÇÃO}

O uso responsável dos recursos naturais, o incentivo a autossustentação e a preservação da biodiversidade são fatores imprescindíveis para prática da produção orgânica. THOMPSON \& NARDONE (1999) enfatizam a importância da aplicação do conceito da integridade funcional para garantir a sustentabilidade. No sistema orgânico de criação de aves, as condições menos agressivas de produção e a característica de rusticidade atribuída a essas aves não eliminam os riscos de ocorrência de doenças no plantel. Nesse sistema de produção, a redução da pressão de infecção ambiental baseia-se em medidas preventivas, sendo recomendado o uso de produtos biodegradáveis para a desinfecção dos aviários e utensílios (JAENISCH, 2008).

Nos estabelecimentos avícolas, compostos de amônia quaternária e hipoclorito de sódio são amplamente utilizados na higienização, no entanto são potencialmente prejudiciais ao meio ambiente. Produtos com princípios ativos biodegradáveis como os ácidos

IPesquisadores da Embrapa Suínos e Aves, CP 21, 89700-000, Concórdia, SC, Brasil. Email: fatima@cnpsa.embrapa.br. *Autor para correspondência.

IICentro de Diagnóstico de Sanidade Animal, CEDISA, Concórdia, SC, Brasil. 
orgânicos são cada vez mais exigidos para a desinfecção nos sistemas de produção animal, no entanto seu uso na avicultura ainda não é uma prática comum.

O objetivo deste estudo foi comparar a atividade antibacteriana entre quatro desinfetantes comerciais frente a três indicadores de contaminação (Escherichia coli, Salmonella Enteritidis e Staphylococcus aureus), na presença e ausência de matéria orgânica e em duas temperaturas distintas.

\section{MATERIAL E MÉTODOS}

Avaliou-se a atividade antibacteriana dos desinfetantes: amônia quaternária, hipoclorito de sódio a $1 \%$ e a $0,1 \%$, ácido peracético e do composto de ácidos orgânicos (cítrico, láctico e ascórbico), diluídos conforme prescrição dos fabricantes e seus respectivos desinibidores (Tabela 1).

Os desinfetantes foram testados frente a três bactérias, as amostras-padrão de Salmonella Enteritidis, (PT4 isolado P125589), Escherichia coli (ATCC 25922) e Staphylococcus aureus (ATCC 25923). Os tratamentos consistiram na utilização de cinco desinfetantes e o grupo controle sem desinfetante, frente a duas temperaturas $\left(10^{\circ} \mathrm{C} \mathrm{e} 30^{\circ} \mathrm{C}\right)$ e na ausência e presença de matéria orgânica, nas seguintes condições: tratamento 1 - desinfetantes, temperatura de $10^{\circ} \mathrm{C}$, sem matéria orgânica; tratamento 2 desinfetantes, temperatura de $10^{\circ} \mathrm{C}$, com matéria orgânica; tratamento 3 - desinfetantes, temperatura de $30^{\circ} \mathrm{C}$, sem matéria orgânica; tratamento 4 - desinfetantes, temperatura de $30^{\circ} \mathrm{C}$, com matéria orgânica; e grupo controle - o grupo controle consistiu em submeter as amostras padrão às mesmas condições citadas anteriormente, porém na ausência de desinfetante.

Protocolo do teste: A metodologia utilizada foi adaptada da diluição em tubos e inoculação em placas conforme descrito por KICH et al. (2004). Foram preparados tubos contendo $1 \mathrm{~mL}$ de suspensão bacteriana, com aproximadamente $10^{8}$ unidades formadoras de colônia (UFC) $\mathrm{mL}^{-1}$, aos quais os pertencentes ao tratamento com matéria orgânica foram adicionados $250 \mu \mathrm{L}$ de soro bovino estéril e aos tubos sem matéria orgânica foram adicionados igual quantidade de PBS. Essa mistura permaneceu em temperatura ambiente por 30 minutos, enquanto os desinfetantes eram diluídos conforme indicação do fabricante. Em seguida, foi acrescido a esses tubos $1 \mathrm{~mL}$ de desinfetante. Esses tubos foram incubados por $20 \mathrm{~min}$ a $10^{\circ} \mathrm{C}$ ou a $30^{\circ} \mathrm{C}$, conforme o tratamento. Os tubos controle foram submetidos às mesmas condições, sendo acrescido $1 \mathrm{~mL}$ de PBS ao invés de desinfetante. Após a incubação, foram adicionados $7,75 \mathrm{~mL}$ do respectivo desinibidor aos tubos de tratamento e a mesma quantidade de PBS aos tubos controle. As amostras foram semeadas em duplicata, em agar nutriente, exceto as do ácido peracético, que foram em agar TSA (Tryptic Soy Agar). A contagem das UFC nas placas foi realizada após 24 horas de incubação, a $37^{\circ} \mathrm{C}$, conforme VARGAS \& WEISS (1994). Foram realizadas cinco repetições para cada tratamento $(1,2,3,4$ e grupo controle) frente às três bactérias, totalizando 360 testes.

A concentração efetiva do desinfetante foi dada pela redução decimal de $4 \log$ da população bacteriana em relação ao grupo controle (DEFRA, 2008).

Análise estatística: para a estatística das unidades formadoras de colônias (UFC), foram utilizadas as médias das contagens. Esses dados foram transformados em $\log (\mathrm{x}+1)$. A avaliação estatística dos dados foi realizada por meio de análise da variância para o modelo que contemplava os efeitos de bloco, desinfetante, matéria orgânica e temperatura e as interações entre os fatores. O desdobramento da análise para o efeito de desinfetante foi realizado por meio do teste de Tukey. As análises descritas foram realizadas

Tabela 1 - Identificação e princípios ativos dos desinfetantes utilizados no presente estudo, diluição de uso recomendada pelo fabricante e respectivos desinibidores.

\begin{tabular}{|c|c|c|c|}
\hline Produto & Princípio ativo & $\begin{array}{l}\text { Diluição } \\
\text { recomendada }\end{array}$ & Desinibidor \\
\hline Amônia quaternária & Cloreto de Alquil dimetil amônio $\left(80 \mathrm{~g} 100 \mathrm{~mL}^{-1}\right)$ & $1: 1500$ & $\begin{array}{l}\text { Caldo nutriente com } 0,5 \% \text { de tween } \\
80 \text { e lecitina } 0,07 \%\end{array}$ \\
\hline Hipoclorito de sódio 1\% & $\begin{array}{l}\text { Hipoclorito de sódio com } 10 \text { a } 12 \% \text { de cloro } \\
\text { ativo }\end{array}$ & $1: 10$ & $\begin{array}{l}\text { Caldo nutriente com } 0,6 \% \text { de } \\
\text { tiossulfato de sódio }\end{array}$ \\
\hline Hipoclorito de sódio $0,1 \%$ & $\begin{array}{l}\text { Hipoclorito de sódio com } 10 \text { a } 12 \% \text { de cloro } \\
\text { ativo }\end{array}$ & $1: 100$ & $\begin{array}{l}\text { Caldo nutriente com } 0,6 \% \text { de } \\
\text { tiossulfato de sódio }\end{array}$ \\
\hline Ácido peracético & $\begin{array}{l}\text { Ácido peracético } 2 \% \text { Peróxido de hidrogênio } \\
6 \% \text { Ácido acético } 22 \%\end{array}$ & $1: 200$ & $\begin{array}{l}\text { Tiossulfato de sódio } 2 \mathrm{~g} \text { litro }^{-1} \text { no } \\
\text { meio de TSA }\end{array}$ \\
\hline $\begin{array}{l}\text { Composto de ácidos } \\
\text { orgânicos }\end{array}$ & $\begin{array}{l}\text { Ácido ascórbico } 1 \mathrm{~mL} \text {, Ácido cítrico } 0,475 \mathrm{~mL} \text {, } \\
\text { Ácido láctico } 0,475 \mathrm{~mL} \quad 100.000 \mathrm{~mL} \text { água } \\
\text { desmineralizada qsp }\end{array}$ & $1: 125$ & $1 \mathrm{~mL}$ de $\mathrm{NAOH} 1 \mathrm{~N}$ \\
\hline
\end{tabular}


com o procedimento GLM do SAS software, do SAS Institute Inc. (2003).

\section{RESULTADOS E DISCUSSÃO}

A avaliação da atividade antibacteriana dos desinfetantes testados demonstrou efeito significativo $(\mathrm{P}<0,05)$ de desinfetante e matéria orgânica nas bactérias avaliadas, evidenciando que a presença de matéria orgânica prejudicou a ação dos desinfetantes. $\mathrm{O}$ efeito da interação entre desinfetante e matéria orgânica foi mais evidente, para as bactérias $S$. Enteritidis e S. aureus. Segundo PINHEIRO et al. (2002), a maioria dos desinfetantes químicos tem a sua atuação antimicrobiana prejudicada pela presença de matéria orgânica.
Não foi observado efeito de temperatura sobre as contagens de UFC para as três bactérias $(\mathrm{P}>0,05)$ e nem da interação da temperatura com os outros fatores. Dessa forma, optou-se por avaliar a média das contagens de UFC das duas temperaturas $\left(10^{\circ} \mathrm{C}\right.$ e $\left.30^{\circ} \mathrm{C}\right)$, conjuntamente, detalhando-se a análise estatística apenas para os fatores desinfetante e matéria orgânica (Tabela 2). Resultados obtidos por $\mathrm{KICH}$ et al. (2004) reportaram que a presença de matéria orgânica interferiu na eficácia dos desinfetantes, porém as temperaturas a que foram expostos não alteraram os resultados frente à Salmonella typhimurium. Segundo MORETRO et al. (2003), a perda da atividade antimicrobiana varia de acordo com o princípio ativo do produto utilizado e a linhagem desafiadora.

Tabela 2 - Médias e erros-padrão das contagens de UFC de S. Enteritidis, Escherichia coli e Staphylococcus aureus expressos em logaritmo na base 10 , em função do desinfetante e da matéria orgânica (MO).

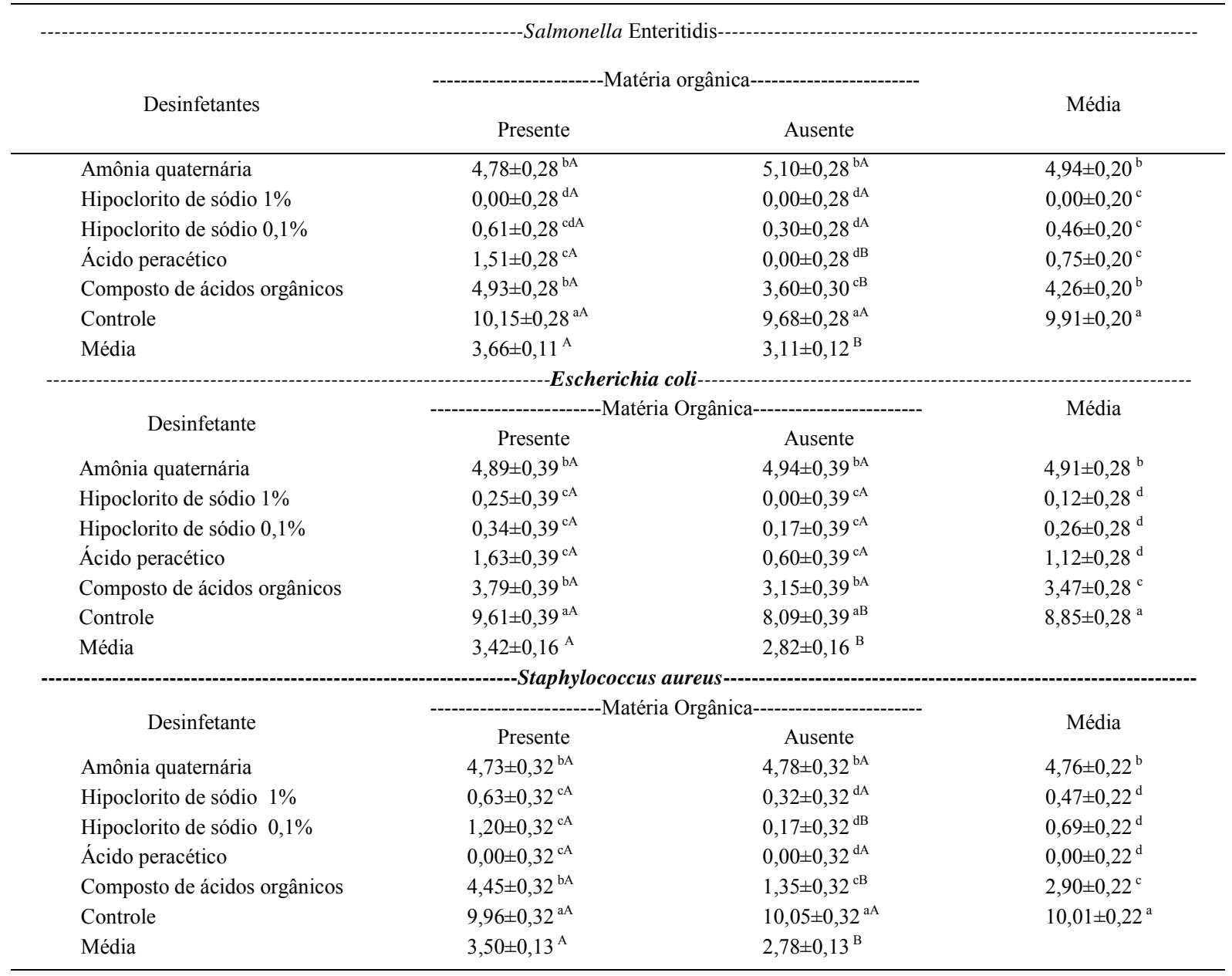

Médias seguidas por letras maiúsculas distintas nas linhas diferem significativamente pelo teste $\mathrm{F}(\mathrm{P}<0,05)$;

Médias seguidas por letras minúsculas distintas nas colunas diferem significativamente pelo teste de Tukey $(\mathrm{P}<0,05)$.

Ciência Rural, v.40, n.2, fev, 2010. 
$\mathrm{Na}$ avicultura, as salmoneloses são patógenos de notificação obrigatória aos serviços oficiais por constituírem um risco à saúde pública, o que justifica a necessidade da eliminação desses agentes, especialmente em plantéis de reprodutores (BRASIL, 2003). Segundo LEITE (2002), essa bactéria apresenta grande resistência frente à amônia quaternária, desinfetante que é amplamente utilizado na avicultura.

Todos os desinfetantes testados foram eficazes obtendo redução decimal de $4 \log$ da população bacteriana em relação ao grupo controle; no entanto, a amônia quaternária e o composto de ácidos orgânicos apresentaram os maiores contagens de UFC.

$\mathrm{Na}$ tabela 2, são apresentados os resultados da atividade antibacteriana dos desinfetantes testados frente à $S$. Enteritidis, à E. coli e ao S. aureus. Para a $S$. Enteritidis, observou-se que o hipoclorito de sódio diluído a $1 \%$ e a $0,1 \%$ foi eficaz mesmo na presença de matéria orgânica. A ação antibacteriana da amônia quaternária não foi alterada na presença de matéria orgânica. O composto de ácidos orgânicos teve sua atividade antimicrobiana prejudicada especialmente pela presença desta.

$\mathrm{Na}$ ausência de matéria orgânica, o ácido peracético reduziu a zero a contagem de UFC frente à $S$. Enteritidis. Esse resultado demonstra que a presença de matéria orgânica reduziu a ação antibacteriana desses desinfetantes à base de ácidos orgânicos.

A ação antibacteriana dos desinfetantes estudados sobre a $\boldsymbol{E}$. coli demonstrou que o desinfetante à base de amônia quaternária apresentou maior contagem de UFC, seguido pelo composto de ácidos orgânicos. GREZZI (2007) reportou que desinfetantes à base de amônia quaternária são bastante sensíveis à presença de matéria orgânica. Frente à $\boldsymbol{E}$. coli, o ácido peracético e o hipoclorito, nas duas diluições, mostraram-se igualmente eficazes.

A análise dos desinfetantes frente ao $\boldsymbol{S}$. aureus mostrou que o ácido peracético e o hipoclorito $1 \%$ foram os mais eficazes, independente da matéria orgânica; porém, na presença desta, o uso do hipoclorito a $0,1 \%$ mostrou aumento significativo de UFC. O composto de ácidos orgânicos apresentou significativa redução do número de UFC em relação à presença de matéria orgânica, ratificando a perda de sua eficácia nessas condições. Frente ao $\boldsymbol{S}$. aureus, a amônia quaternária foi a menos eficaz quando comparada aos demais.

A higienização das instalações avícolas associada ao vazio sanitário é fundamental para minimizar os riscos de infecções e promover a quebra do ciclo de vida de agentes patogênicos (JAENISCH et al., 2004). Nesse processo, a eficácia dos produtos utilizados na desinfecção é fundamental para o controle de agentes infecciosos. O uso de produtos efetivos e não deletérios ao meio ambiente tornou-se um grande desafio nos programas de biosseguridade na produção animal. Tradicionalmente, desinfetantes à base de hipoclorito de sódio e amônia quaternária têm sido utilizados mesmo sendo potencialmente prejudiciais ao meio ambiente. Neste trabalho, tanto o ácido peracético, que é biodegradável, quanto o hipoclorito de sódio a $1 \%$ e a $0,1 \%$ de cloro ativo mostraram-se eficazes frente às bactérias testadas. Porém, a presença de matéria orgânica reduziu a eficácia do ácido peracético frente à $S$. Enteritidis e a do hipoclorito de sódio $0,1 \%$ contra $S$. aureus. $\mathrm{O}$ composto de ácidos orgânicos e a amônia quaternária mostraram perda da sua atividade antibacteriana especialmente na presença de matéria orgânica.

\section{CONCLUSÕES}

O hipoclorito de sódio a $1 \%$ e a $0,1 \%$ de cloro ativo e o ácido peracético foram os desinfetantes que apresentaram maior eficácia frente às amostras testadas. A amônia quaternária e o composto de ácidos orgânicos (cítrico, láctico e ascórbico) foram os menos eficazes.

A presença da matéria orgânica reduziu a atividade antibacteriana nos desinfetantes à base de ácidos orgânicos, produtos que detêm a característica de serem biodegradáveis. Porém, na ausência desta, o ácido peracético mostrou-se o mais eficaz frente à $S$. Enteritidis, atuando com eficácia independente da matéria orgânica contra $\boldsymbol{E}$. coli e $\boldsymbol{S}$. aureus. O ácido peracético revelou-se uma opção válida para a utilização na avicultura orgânica, desde que a desinfecção seja precedida de limpeza criteriosa.

\section{AGRADECIMENTO}

Os autores agradecem ao Dr. Paul Barrow, do Agricultural \& Food Research Council (AFRC)-Intitute for Animal Health, Houghton Laboratory, Cambridge, Inglaterra, pela amostra cedida de Salmonella Enteritidis (PT4 isolado P125589), para uso em experimentação.

\section{REFERÊNCIAS}

BRASIL. Ministério da Agricultura e do Abastecimento. Instrução normativa SDA n. 78/2003, de 03 de novembro de 2003. Diário Oficial da República Federativa do Brasil, Brasília, DF, 5 nov. 2003. Disponível em: <http:// www.agricultura.gov.br/das legislações $>$. Acesso em: 22 jan. 2009 . 
GREZZI G. Limpeza e desinfecção na avicultura. In: CONFERÊNCIA APINCO DE CIÊNCIA E TECNOLOGIA, 2007, Campinas, SP. Anais... Campinas, SP: FACTA, 2007. p.161- 182 .

DEFRA.Department for environment food and rural affairs. Microsoft word explanatory notes, 2008. Disponível em: <http://www.defra.gov.uk/vla/services/docs/ ser_disinfectants.pdf>. Acesso em 21 set. 2009.

JAENISCH, F.R.F. et al. Importância da higienização na produção avícola. Concórdia, SC: Embrapa Suínos e Aves, 2004. 5p. (Embrapa Suínos e Aves. Comunicado Técnico, 363). Disponível em: <www.cnpsa.embrapa.br/sgc/ sgc_publicacoes/cot363.pdf>. Acesso em 10 ago. 2009.

JAENISCH, F.R.F. Perfil higiênico sanitário do frango orgânico. Avicultura Industrial, v.99, n.1163, p.12-14, 2008.

KICH, J.D. et al. Avaliação da atividade antibacteriana de seis desinfetantes comerciais frente a amostras de Salmonella typhimurium isoladas de suínos. Acta Scientiae Veterinariae, v.32, n.1, p.33-39, 2004.

LEITE, C.R.C. Desinfecção química aplicada na avicultura: concentrações inibitórias mínimas de desinfetantes derivados da amônia quaternária e hipoclorito de sódio sobre Salmonella sp. e Escherichia coli. Acta Scientiae Veterinariae, v.30, n.1, p.74-75, 2002.

MORETRO T. et al. Susceptibility of Salmonella isolated from fish feed factories to disinfectants and airdrying at surfaces. Veterinary Microbiology, v. 4, p.207-217, 2003. Disponível em: <http:// www.sciencedirect.com/science?_ob=ArticleURL\&_udi=B6TD6$48 \mathrm{KFGND}-2 \&$ user $=687358 \&$ rdoc $=1 \& \mathrm{fmt}=\&$ orig $=$ search \&_sort $=$ d\&_docanchor $=\&$ view $=c \&$ c search StrId $=115$ $3776714 \&$ rerunOrigin $=$ google \& acct $=\mathrm{C} 0000$ $37899 \&$ version $=1 \&$ url Version $=0$ \& userid $=68$ $7358 \& \mathrm{md} 5=\mathrm{c} 55525 \mathrm{c} 9 \mathrm{ae} 396 \mathrm{a} 70 \mathrm{~b} 81581 \mathrm{c} 7 \mathrm{~d} 3 \mathrm{~d} 0 \mathrm{~b} 03 \mathrm{~d}>$. Acesso em: 25 ago. 2009. doi: 10.1016/S0378-1135(03)00105-6.

PINHEIRO, S.R. et al. Influência da matéria orgânica na atividade micobactericida de cinco desinfetantes de uso pecuário. Brazilian journal of veterinary research and animal science, v.29,n. 1, p.51-60, 1992.

SAS INSTITUTE INC. System for Microsoft Windows: release 9.1. Cary, 2002-2003. 1 CD-ROM.

VARGAS A. C.; WEISS R.D.N. Avaliação da atividade antibacteriana in vitro do proxitane. Chapecó: Sanita_Biomaster 1994. Informação Técnica PROXITANE â 1512 .

THOMPSON, P.B.; NARDONE, A. Sustainable livestock production; methodological and crithical challenges. Livestock Production Science, v.61, n.2, p.111-119, 1999. 